\title{
Changes in the reporting of ventilator-associated pneumonia
}

\author{
Jeremy Whiting BS, Hawa Edriss MD, Nina Ngo BSN, Lacy Phillips MSN
}

\section{Case}

A 54-year-old man with a history of chronic obstructive pulmonary disease presented to the emergency department with shortness of breath and cough consistent with an acute COPD exacerbation. He was subsequently intubated due to hypercapnea. His ICU stay was unremarkable until he developed a fever of $102.3^{\circ} \mathrm{F}$ and leukocytosis $\left(16,700 \mathrm{WBC} / \mathrm{mm}^{3}\right)$. Chest $\mathrm{x}$-ray showed a new right upper lobe infiltrate on days 5 and 6 . Respiratory therapy noted white sputum was being collected on endotracheal suction. The patient required additional ventilator support as noted in the below table. Did this patient develop a ventilator-associated pneumonia?

\begin{tabular}{|l|l|l|l|l|l|}
\hline & Day3 & Day4 & Day5 & Day6 & Day7 \\
\hline Minimum $\mathrm{FiO}_{2}$ & 40 & 40 & 50 & 60 & 60 \\
\hline Minimum PEEP & 5 & 5 & 8 & 5 & 5 \\
\hline
\end{tabular}

Corresponding Author: Jeremy Whiting BS

Author Contact Information : Jeremy.whiting@ttuhsc.edu DOI: 10.12746/swrccc2013.0104.041

\section{Discussion}

Patients on mechanical ventilators are at an increased risk to develop a variety of ventilatorassociated complications. The most important complication is ventilator-associated pneumonia (VAP). The U.S. Centers for Disease Control and Prevention (CDC) tracks healthcare-associated infections like VAP under the auspices of their National Healthcare Safety Network (NHSN, formerly known as the National Nosocomial Infection Surveillance System or NNIS). The NHSN and its predecessor have attempted to track VAP under a variety of protocols, with its last revision, known as the PNEU protocol, released in 2002. In January 2013, the NHSN instituted a major overhaul of its reporting criteria with the updated ventilator-associated events (VAE) protocol. ${ }^{2}$

\section{Frequency}

The incidence of ventilator-associated pneumonia has been difficult to establish. A 2002 metaanalysis found that between $8 \%$ and $28 \%$ of patients on mechanical ventilation developed VAP worldwide. ${ }^{3}$ A more recent study of North American hospitals found an incidence rate between $5.7 \%$ and $9.7 \%{ }^{4}$ while the $2011 \mathrm{NHSN}$ report found an incidence rate of 0.0-4.9 VAP per 1000 ventilator days. ${ }^{5}$ It is thought that the NHSN incidence rates are artificially low due to vagueness of the PNEU standard, especially since rates of VAP are an order of magnitude higher in Europe even with similar prevention strategies. ${ }^{6}$ There is currently no "gold standard" to clinically identify VAP, although most observers agree that histological identification is the most accurate method. 


\section{Consequences}

VAP is associated with significant costs, morbidity, and mortality. VAP patients had $\$ 35,000$ more in hospital costs than those who did not develop VAP. ${ }^{7}$ Since Medicare and Medicaid reimbursements are based on the primary diagnosis at the time of admission, subsequent nosocomial infections like VAP result in a loss for the hospital. ${ }^{7}$ A large meta-analysis found that mortality rates roughly doubled in patients who developed VAP. ${ }^{8}$ Patients who develop VAP stay in the ICU for 5-7 days longer. ${ }^{8}$ In addition, the pathogens found in VAP patients tend to be drug resistant. For example, $50-80 \%$ of patients who develop Staphylococcus aureus VAP are found to have the methicillin-resistant strain (MRSA). ${ }^{9}$

\section{Old CDC Criteria: PNEU}

The old NNIS/NHSN definition first released in 2002 is known as the PNEU protocol. Three levels of pneumonia were identified and reported under the standard, labeled as clinically defined pneumonia (PNU1), pneumonia with specific laboratory findings (PNU2), and pneumonia in immunocompromised patients (PNU3). The protocol was not specific for VAP but was developed for all types of healthcare-associated pneumonias. If a patient met the requirements for PNU1, PNU2, or PNU3 and the patient was on mechanical ventilation during the 48-hour period prior to the onset of the pneumonia, the infection was considered to be a VAP. Special criteria were established for pediatric patients, the immunocompromised and the elderly. ${ }^{1}$

\section{Critique of the Old Criteria}

Although the PNEU protocol has been widely used, it has a number of limitations. Several of the items, like changes in x-ray and development of a fever or leukocytosis, are not specific markers of pneumonia. Vague definitions like "worsening gas exchange" and "change in character of sputum" make the protocol difficult to apply consistently (see Figure 1). Items like new onset or worsening cough, dyspnea, and tachypnea are almost impossible to assess in sedated patients. As a result, interobserver variability is high. ${ }^{10}$

\section{New CDC Criteria: VAE}

The new NHSN protocol seeks to identify patients with ventilator-associated events (VAE), a broad definition meant to include all types of ventilator complications, including VAP. Ventilated patients are screened for signs of worsening oxygenation (see Fig. 1 for specifics). If the criteria are met, the patient is identified as having a ventilator-associated condition (VAC). From there, key parameters like temperature and white blood cell count are analyzed to determine if the patient has developed an infection-related ventilator-associated complication (IVAC). A more detailed review of the patient's chart is necessary if a patient meets both the VAC and IVAC criteria. The last stage in the VAE protocol examines factors like respiratory secretions and respiratory cultures to determine if the patient has developed a possible or probable VAP. ${ }^{2}$

The new protocol makes the initial review of all patient records much quicker. In fact, the mean chart review time dropped from 39 minutes to 1.8 minutes when investigators switched from the old PNEU criteria to a protocol similar to the new VAC criteria." Relatively simple algorithms can be used by hospitals to screen the medical records of all mechanically ventilated patients and identify those patients who have a VAC and therefore require further scrutiny.

An important note about the new protocol is that it was not designed for use by clinicians when treating VAP. The protocol is used retrospectively or concurrently for VAE surveillance and does not provide clinical tools like treatment recommendations. 


\section{Criticism of the VAE Protocol}

Unfortunately, the new VAE protocol has introduced some new problems. One of the limitations of the new protocol is that it still places a heavy emphasis on VAP and makes no effort to identify other types of complications found in mechanically ventilated patients. Also, some patients with extremely poor pulmonary function may already have very high $\mathrm{FiO}_{2}$ and PEEP values, leaving no room for worsening oxygenation. From a practical standpoint, the minimum $\mathrm{FiO}_{2}$ and PEEP frequently does not reflect the actual lung function due to continual manipulation by physicians, respiratory therapists, and others attempting to wean the patient off the ventilator. Trying a lower $\mathrm{FiO}_{2}$ or PEEP for a few minutes could create an artificially low daily minimum.

\section{Hospital Responsibilities for Reporting VAP}

Healthcare facilities in 32 states are required by state law to report their healthcare-associated infection data to the NHSN. ${ }^{12}$ Hospitals and other facilities in other states voluntarily submit data for infection tracking, often as a result of pressure from insurers or local health departments. ${ }^{10}$ Hospitals in the NHSN with ventilated patients are required to undergo VAE surveillance.

Results for individual hospitals are published online at www.medicare.gov/hospitalcompare. On this website the public is able to select multiple hospitals and compare performance measures such as pneumonia, heart attacks, heart failures, and surgeries.

At our hospital, the Infection Control Department does manual surveillance for VAE. Additionally, the hospital utilizes an electronic surveillance database called MedMined ${ }^{\circledR}$ (CareFusion San Diego, CA).

\section{Case Conclusion}

The opening case meets the old CDC PNEU criteria for a VAP but does not meet the qualifications under the new VAE protocol. The case shows a new, persistent infiltrate with fever, leukocytosis, new sputum, and increased $\mathrm{O}_{2}$ requirement, providing enough information to classify this as PNU1 or "Clinically defined pneumonia" under the PNEU criteria. However, the new VAE criteria include specific rules about worsening oxygenation that were not met by this patient. The daily minimum $\mathrm{FiO}_{2}$ slowly increased by 20 $\%$ and there was an increase of $3 \mathrm{cmH}_{2} \mathrm{O}$ in PEEP for one day but the protocol requires an abrupt jump in either $\mathrm{FiO}_{2}$ or PEEP requirement sustained for 2 days. Since the VAC conditions were never met, a VAE will not be reported, no matter how convincing the rest of the evidence may be. It is important to note that this patient likely requires medical intervention to treat pneumonia but as far as government reporting is concerned, the patient did not develop a possible or probable VAP under the new standard.

\section{Key Points}

1. The CDC has transitioned from its old ventilator-associated pneumonia rules to a new set of guidelines that try to identify any ventilator-associated complications. The broad term "ventilator-associated event" is used to describe these complications and is characterized by worsening oxygenation.

2. The new VAE definition was not designed for use in day-to-day patient management but was created for hospital quality tracking and possible public reporting and could be incorporated into pay-for-performance initiatives. However, it is helpful for clinicians to understand how their patients and performance are being monitored and reported to outside agencies.

Key words - ventilator-associated pneumonia, ventilatorassociated event, mechanical ventilation, healthcare-associated infection 
Figure 1.

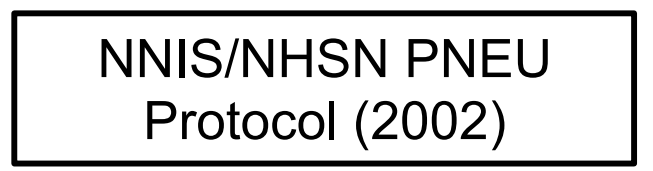

X-ray: 2 or more serial radiographs with one of the following:

-New or progressive and persistent infiltrate

-Consolidation

-Cavitation

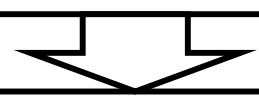

At least 1 of the following:

-Fever $>38^{\circ} \mathrm{C}$ with no other cause -Leukopenia (<4000 WBC/mm $\left.\mathrm{mm}^{3}\right)$ or leukocytosis (>12,000 WBC/ $\mathrm{mm}^{3}$ )

-Altered mental status with no other cause in $\geq 70$ y.o.

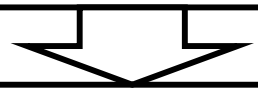

At least 2 of the following:

-New onset of purulent sputum, or change in character of sputum, or increase in respiratory secretions, or increase in suctioning requirements

-New onset or worsening cough, or dyspnea, or tachypnea

-Rales or bronchial breath sounds

-Worsening gas exchange (like

$\mathrm{O}_{2}$ desats, increased $\mathrm{O}_{2}$ requirement, increased ventilation demand)

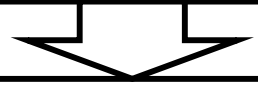

PNU1 (Clinically defined pneumonia) criteria met
NHSN VAE Protocol (2013)

Baseline period of stability:

Daily minimum PEEP or daily minimum $\mathrm{FiO}_{2}$ is stable or decreasing for 2 or more calendar days

\begin{tabular}{l} 
Period of worsening \\
oxygenation: \\
Daily minimum PEEP \\
increases to $\geq 3 \mathrm{cmH}_{2} \mathrm{O}$ \\
over the baseline value \\
for 2 or more calendar \\
days or daily minimum \\
$\mathrm{FiO}_{2}$ increases to $\geq 0.20$ \\
over the baseline value \\
for 2 or more calendar \\
days \\
\hline \multicolumn{2}{|c|}{ VAC (Ventilator- } \\
associated condition) \\
criteria met
\end{tabular}


Author Affiliation: Jeremy Whiting and Nina Ngo are medical students at TTUHSC, Lubbock, TX. Hawa Edriss is an Internal Medicine resident at TTUHSC, Lubbock, Tx. Lacy Phillips is a critical care nurse at University Medical Center, Lubbock, TX.

Received: 06/13/2013

Accepted: 08/30/2013

Reviewers: Richard Winn MD, Isham Huizar MD

Published electronically: 10/15/2013

Conflict of Interest Disclosures: None

\section{REFERENCES}

1. Horan TC, Andrus M, Dudeck MA. CDC/NHSN surveillance definition of health care-associated infection and criteria for specific types of infections in the acute care setting. Am J Infect Control. 2008 Jun; 36(5):309-32. doi: 10.1016/j.ajic.2008.03.002. Erratum in: Am J Infect Control. 2008 Nov; 36(9):655. PubMed PMID: 18538699.

2. Centers for Disease Control and Prevention. Surveillance for ventilator-associated events. http://www.cdc.gov/nhsn/acutecare-hospital/vae/index.html.

3. Chastre J, Fagon JY. Ventilator-associated pneumonia. Am $J$ Respir Crit Care Med. 2002 Apr 1; 165(7):867-903. Review. PubMed PMID: 11934711.

4. Kollef MH, Afessa B, Anzueto A, Veremakis C, Kerr KM, Margolis BD, Craven DE, Roberts PR, Arroliga AC, Hubmayr RD, Restrepo MI, Auger WR, Schinner R; NASCENT Investigation Group. Silver-coated endotracheal tubes and incidence of ventilator-associated pneumonia: the NASCENT randomized trial. JAMA. 2008 Aug 20; 300(7):805-13. doi: 10.1001/ jama.300.7.805. PubMed PMID: 18714060.

5. Dudeck MA, Horan TC, Peterson KD, Allen-Bridson K, Morrell G, Anttila A, Pollock DA, Edwards JR. National Healthcare Safety Network report, data summary for 2011, device-associated module. Am J Infect Control. 2013 Apr; 41(4):286-300. doi: 10.1016/j.ajic.2013.01.002. PubMed PMID: 23538117.

6. Klompas M. Complications of mechanical ventilation--the CDC's new surveillance paradigm. $N$ Engl J Med. 2013 Apr 18; 368(16):1472-5. doi: 10.1056/NEJMp1300633. PubMed PMID: 23594002 .
7. Restrepo MI, Anzueto A, Arroliga AC, Afessa B, Atkinson MJ, Ho NJ, Schinner R, Bracken RL, Kollef MH. Economic burden of ventilator-associated pneumonia based on total resource utilization. Infect Control Hosp Epidemiol. 2010 May; 31(5):509-15. doi: 10.1086/651669. PubMed PMID: 20302428.

8. Safdar N, Dezfulian C, Collard HR, Saint S. Clinical and economic consequences of ventilator-associated pneumonia: a systematic review. Crit Care Med. 2005 Oct; 33(10):2184-93. Review. PubMed PMID: 16215368.

9. Barbier F, Andremont A, Wolff M, Bouadma L. Hospital-acquired pneumonia and ventilator-associated pneumonia: recent advances in epidemiology and management. Curr Opin Pulm Med. 2013 May; 19(3):216-28. doi: 10.1097/ MCP.0b013e32835f27be. PubMed PMID: 23524477.

10. Klompas M. Interobserver variability in ventilator-associated pneumonia surveillance. Am J Infect Control. 2010 Apr; 38(3):237-9. doi:

10.1016/j.ajic.2009.10.003. Epub 2010 Feb 19. PubMed PMID: 20171757.

11. Klompas M, Khan Y, Kleinman K, Evans RS, Lloyd JF, Stevenson K, Samore M, Platt R; CDC Prevention Epicenters Program. Multicenter evaluation of a novel surveillance paradigm for complications of mechanical ventilation. PLoS One. 2011 Mar 22; 6(3):e18062. doi: 10.1371/journal.pone.0018062. PubMed PMID: 21445364; PubMed Central PMCID: PMC3062570.

12. Centers for Disease Control and Prevention. Facilities in these states are required by law to report HAI data to NHSH. http:// www.cdc.gov/hai/stateplans/required-to-report-hai-NHSN.html 